\title{
Styrene Epoxidation over Cobalt Cyclam Immobilized SBA-15 Catalyst
}

\author{
Sujandi, Eko Adi Prasetyanto. Sang-Cheol Han, and Sang-Eon Park ${ }^{*}$ \\ Lab. of Nano-Green Catalysis and Nano Center for Fine Chemicals Ftsion Technology, Department of Chemistry, \\ Inha University, Incheon 402-751, Korea. "E-mail: separkainha.ack \\ Received May 19, 2006
}

\begin{abstract}
Cobalt (cyclam) complex has been successfully immobilized onto SBA-15, and proven to be an active catalyst for the epoxidation of styrene with tert-butyl hydroperoxide as a terminal oxidant. The selectivity for styrene oxide was observed to be up to $66 \%$ with $40 \%$ styrene conversion after $12 \mathrm{~h}$ reaction time. The reversible redox cycle between $\mathrm{C}$ (III) and $\mathrm{C}$ (II) couple which was supposed to play key role during the epoxidation reaction was supported by a cyclic voltametry analysis. The textural properties of the catalyst was characterized by $\mathrm{XRD}, \mathrm{N}_{2}$ adsorption-desorption, and TEM analysis.
\end{abstract}

Key Words : Co, SB $\Lambda-15$, IIeterogeneous catalyst, Epoxidation, Styrene

\section{Introduction}

Ordered mesoporous silica materials have opened many new possibilities for applications in the field of heterogeneous catalysis, adsorption, and separation due to their large, well-defined pore sizes and high surface areas. However, for the practical applications in catalysis, these materials have been suffered from lack of active sites due to the inert nature of the silica surface. In recent years, surface functionalization with catalytic homogeneous systems especially metal complexes has been widely applied in order to generate active sites onto these mesoporous silica material surfaces. The immobilization of catalytically active metal complexes onto the surfaces offered advantages of combination of high catalytic activity, selectivity and stability with easier separation of the catalysts from the reaction media. ${ }^{1.2}$

Among the variety of catalytically active metal complexes that have been functionalized onto mesoporous silica material surfaces, the transition metal complexes which were active in epoxidation of olefins have been studied numerously. ${ }^{3}$ Indeed, it is a particularly useful oxidation reaction since epoxides are important intermediates for many chemical and fine chemical products. Cobalt salts and cobalt complexes are among the most widely used homogenous catalysts in the partial oxidation of hydrocarbons. ${ }^{+}$ The reversible redox cycle of the cobalt species is acknowledged as the key in the catalytic cycle. ${ }^{5}$ Therefore, in this work we immobilized cobalt cyclam complex onto the SBA15 mesoporous silica surface and tested as a heterogeneous catalyst in epoxidation of styrene with tert-butyl hydroperoxide (TBHP) as the terminal oxidant. The cyclam has been a well known macrocyclic ligand that can accommodate and stabilize various high oxidation state transition metal cotions. $^{67}$ Its transition metal complexes have been studied for the olefins oxidation in the homogeneous system. ${ }^{8}$

\section{Experimental Procedures}

Chemicals. Sodium metasilicate $\left(\mathrm{Na}_{2} \mathrm{SiO}_{3} \cdot 9 \mathrm{H}_{2} \mathrm{O}\right.$; Sigma
Aldrich) and 3-chloropropyl triethoxysilane/CPTS (Cl $\left(\mathrm{CH}_{2}\right)_{3} \mathrm{Si}(\mathrm{OEt})_{3}$; Aldrich) were used as silica and chloropropyl group sources, respectively. A Pluronic P123 triblock copolymer (poly(ethyleneoxide)-poly(propylene-oxide)poly(ethyleneoxide) $/ \mathrm{EO}_{20} \mathrm{PO}_{70} \mathrm{EO}_{20} ; \mathrm{MW5} 800$; BASF), was used as a structure directing agent. $\mathrm{CoCl}_{2} \cdot 6 \mathrm{H}_{2} \mathrm{O}$, styrene, tert-butyl hydroperoxide ( $70 \%$ in $\mathrm{H}_{2} \mathrm{O}$ ), hydrogen peroxide ( $35 \%$ in $\mathrm{H}_{2} \mathrm{O}$ ) and HPLC grade acetonitrile solvent were purchased from Aldrich. The tetraazamacrocycle (cyclam) was synthesized according to the reported procedure.?

Synthesis of Chloropropyl-functionalized SBA-15 (Clpr-SBA-15). The mixed gel of Pluronic P123 surfactant (4 g), sodium metasilicate (11.2 g), and 3-chloropropyltriethoxysilane $(0.5 \mathrm{~g})$ in $2 \mathrm{M} \mathrm{HCl}$ solution $(135 \mathrm{~g})$ was digested with stirring for 1 hour at $313 \mathrm{~K}$ to get the reactive gel. The molar composition of the gel mixture was: $\mathrm{SiO}_{2}$ : CPTS : $\mathrm{P} 123: \mathrm{HCl}: \mathrm{H}_{2} \mathrm{O}=1.0: 0.05: 0.018: 11.0: 117.1$. The obtained reactive gel was subjected to microwave digestion system (CEM Corporation, MARS-5) in which the condition for crystallization was set under static conditions at $373 \mathrm{~K}$ for $2 \mathrm{~h}$ at an operated power of $300 \mathrm{~W}(100 \%)$. The crystallized product was filtered, washed with warm distilled water, and dried at $333 \mathrm{~K}$. The surfactant was then selectively removed by Soxhlet extraction over the acidified ethanol for $24 \mathrm{~h}$.

Cobalt Cyclam Functionalized SBA-15 (Co(cyclam)SBA-15). A mixture of cyclam $(0.5 \mathrm{~g}, 2.5 \mathrm{mmol})$, ClprSBA- $15(1.00 \mathrm{~g})$ in $90 \mathrm{~mL}$ of acetonitrile and triethylamine $(1.1 \mathrm{~g}, 10.9 \mathrm{mmol}$ ) was refluxed at $363 \mathrm{~K}$ with stirring for 2 days. The excess cyclam was removed by Soxhlet extraction over ethanol for 24 hours. After drying under vacuum at 373 $\mathrm{K}$ for $24 \mathrm{~h}$, the resulting cyclam functionalized SBA-15 (Cyclam-SBA-15) was dispersed into $90 \mathrm{~mL}$ ethanolic solution of $0.5 \mathrm{~g} \mathrm{CoCl}_{2} \cdot 6 \mathrm{H}_{2} \mathrm{O}$ and refluxed for $12 \mathrm{~h}$. During this process, the reaction mixture was constantly bubbled with air in order to oxidize the Co (cyclam) to Co ${ }^{\text {III }}$ (cyclam) complex to yield Co(cyclam)-SBA-15 catalyst (Scheme 1). The green solid particle was filtered, washed with dilute $\mathrm{HCl}$ solution and distilled water, and dried at $333 \mathrm{~K}$. From the 
atomic absorption spectroscopy analysis it was found that the loading of Co was $0.40 \mathrm{mmol} / \mathrm{g}$ of catalyst.

Styrene Epoxidation. A mixture of $100 \mathrm{mg}$ catalyst, styrene $(1 \mathrm{~g}, 10 \mathrm{mmol}), 10 \mathrm{ml}$ acetonitrile, and TBHP, $70 \%$ in water, $(5.6 \mathrm{~g}, 20 \mathrm{mmol})$ was introduced to the reaction vesse] and heated at $313 \mathrm{~K}$ with constant stirring. A dodecane was use as intemal standard. Small amount of reaction mixture was frequently removed from the reaction vessel and subsequently the reaction products were analyzed by using a Donam DS 6200 gas chromatograph equipped with an HP-5 capillary column $(0.32 \mathrm{~mm} \times 30 \mathrm{~m})$ and an FID detector. Products identification was done base on GC peaks of the authentic compounds and GC-MS analysis. The conversion was calculated based the initial amount of styrene, the selectivity was calculated based on total amount of products. Styrene oxidation with aqueous hydrogen peroxide over Co(cyclam)-SBA-15 was done under similar reaction condition except the used of $\mathrm{H}_{2} \mathrm{O}_{2}(35 \%)$ instead of tert-butyl hydroperoxide.

Catalyst Characterization. The obtained materials were characterized with several spectroscopic techniques in order to confirm the crystallinity and functionality. The structure and crystallinity of the materials were determined using powder X-ray diffraction (XRD) pattens which were obtained on a Rigaku diffractometer using CuK $\alpha$ radiation $(\lambda=0.154 \mathrm{~nm}) . \mathrm{N}_{2}$ adsorption-desorption isotherms and pore characterizations were obtained by using a Micromeritics ASAP 2020 apparatus at liquid $\mathrm{N}_{2}$ temperature. Transmission electron microscopic (TEM) images were taken using a JEM-3011 instrument (JEOL) equipped with a slow-scan CCD camera operating at $300 \mathrm{keV}$. UV-Vis-NIR diffuse reflectance spectra (DRS) were measured with a Solidspec 3700 UV-Vis-NIR spectrometer. For analysis, sample was loaded into a homemade quartz cell and evacuated under vacuum at $423 \mathrm{~K}$. The NIR spectra were recorded in the reflectance mode at room temperature. The cyclic voltammogram was recorded on a Solartron Electrochemical
Interface unit (mode] SI 1287) and carried out in unstirred $\mathrm{LiClO}_{4}$ solution with a potential sweep rate of $20 \mathrm{mVs}^{-1}$ from -0.55 to $1.1 \mathrm{~V}$ versus $\mathrm{SCE}$.

\section{Results and Discussion}

Preparation and Characterization of Co(cyclam)-SBA15. The chloropropyl tethered SBA- 15, Clpr-SBA-15 was synthesized as a parent material for the generation of Cyclam-SBA-15 and Co(cyclam)-SBA-15. Chloropropyl tethered mesoporous material has been widely used as an intermediate for the functionalization of mesoporous materials because the chloro- groups can be easily modified by nucleophilic substitution for further immobilization of a wide range of ligands and metal complexes. ${ }^{10-12}$ In this work, the Clpr-SBA-15 was directly synthesized by using microwave synthesis under strong acidic condition in order to obtain well dispersed chloropropyl groups quantitatively, beside advantages of rapid homogeneous heating, fast and efficient crystallization, and reducing synthesis routes. ${ }^{13-15}$ Figure 1. shows the small-angle X-ray diffraction pattem, TEM image, $\mathrm{N}_{2}$ adsorption-desorption full isotherm and pore size distribution of the obtained Clpr-SBA-15. The XRD pattern showed three well-resolved peaks with a very intense diffraction peak at $2 \theta=1.0^{\circ}$ and two peaks with lower intensity at higher degree (1.6 and $\left.1.9^{\circ}\right)$ which were indexed to the 100,110 , and 200 planes characteristic for highly ordemess and excellent textural unifonnity of a SBA15 mesoporous material with a mesostructure of hexagonal space group symmetry $p 6 \mathrm{~mm}^{16}$ Further evidence for a highly ordered mesostructure was provided by transmission electron microscopy (TEM) image. The TEM image clearly showed that the material had an array of highly ordered 2-D hexagonal structure which was similar to those of pure SBA15 materials. The $\mathrm{N}_{2}$ adsorption-desorption isotherms of the sample exhibited well defined type IV isotherm with H1type hysterisis loops which was the characteristic for
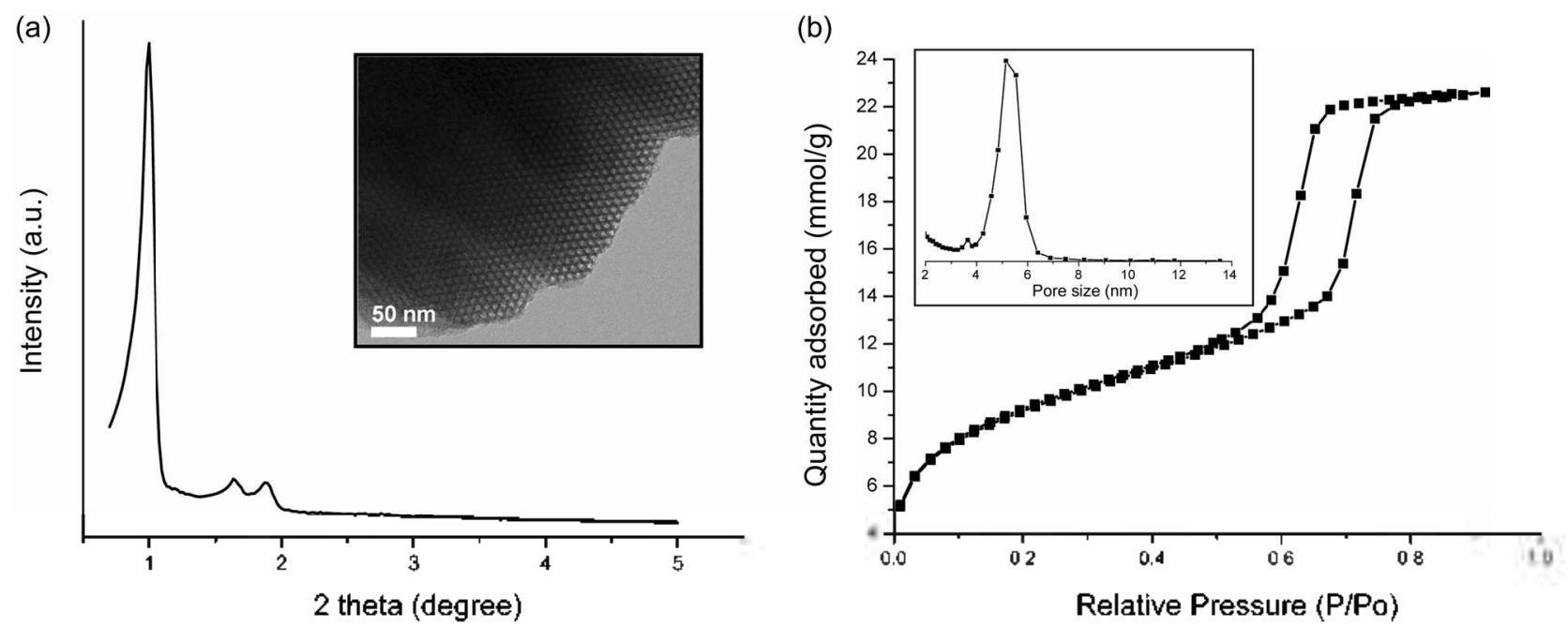

Figure 1. (a) XRD pattern and TEM image (inlet) of Clpr-SBA-15 synthesized by using direct synthesis under microwave irradiation (inlet: TEM image of Clpr-SBA-15). (b) $\mathrm{N}_{2}$ adsorption-desorption full isotherm and pore size distribution calculated by BJH method from desorption branch (inlet) of $\mathrm{Clpr}-\mathrm{SBA}-15$. 
mesoporous materials having cylindrical type mesostructures that facilitate the condensation of $\mathrm{N}_{2}$. The sharp increase in adsorption step at relative pressure $\mathrm{P} / \mathrm{Po}$ of 0.75 indicated that the obtained material posses large pore size with narrow distribution. This was confirmed by the pore size distribution calculated by using a $\mathrm{BJH}$ method from the desorption branch which exhibited narrow pore distribution with maxima at $5.1 \mathrm{~nm}$. The clear evidence for the successful incorporation of the chloropropyl moieties onto the SBA-15 surface was provided by ${ }^{13} \mathrm{C}$ solid NMR, NIR and FTIR spectra. ${ }^{17}$ The TGA and elemental analysis revealed that the chloropropyl groups were quantitatively incorporated from the initial gel mixture.

The surface chemical modification on the Clpr-SBA-15 was done with the cyclam substitution reaction following by accommodation of cobalt (III) species in order to obtain the Cyclam-SBA-15 and Co(cyclam)-SBA-15, respectively (Scheme 1). The small angle XRD patterns of Cyclam-SBA15 and Co(cyclam)-SBA-15 (not shown) were still very similar to that of the parent Clpr-SBA-15. It told that the highly ordered mesostructure was maintained during the whole chemical transformation processes. The $\mathrm{N}_{2}$ adsorption-desorption analysis exhibited that the well defined type IV isotherms with H1-type hysterisis loops were maintained implying that the materials kept possessing the large mesopores with narrow pore-size distribution. The ClprSBA- 15 had large mean pore size of $5.1 \mathrm{~nm}$ which could be accessible and substituted by cyclam. The resulted CyclamSBA-15 and Co(cyclam)-SBA-15 had mean pore sizes of 4.8 and $4.6 \mathrm{~nm}$, respectively. The BET surface area of Clpr-
SBA- 15 was found to be $702 \mathrm{~m}^{2} / \mathrm{g}$ and was significantly reduced to $364 \mathrm{~m}^{2} / \mathrm{g}$ and $358 \mathrm{~m}^{2} / \mathrm{g}$, respectively, due to the accommodation of the bulky cyclam and Co(III)cyclam complex inside the mesopores.

The successful chemical transfomation of the Clpr-SBA15 into Cyclam-SBA- 15 and Co(cyclam)-SBA-15 were traced by near infrared (NIR). The chemical modification of chloro- groups with cyclam was confirmed with the appearance of the absorption band for the secondary amine of cyclam in the NIR spectra at $1550 \mathrm{~nm} .^{18}$ The higher intensity and area of the $\mathrm{CH}_{2}$ reflectance band at 2265-2350

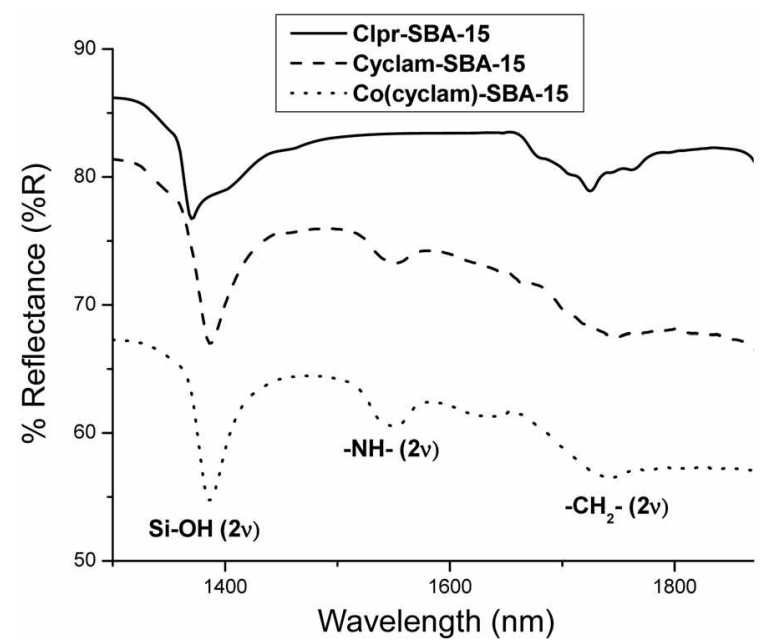

Figure 2. NTR spectra of $\mathrm{Clpr}-\mathrm{SB} \Lambda-15$, Cyclam-SB $\mathrm{S}-15$ and Co(cyclam)-SBA-15.

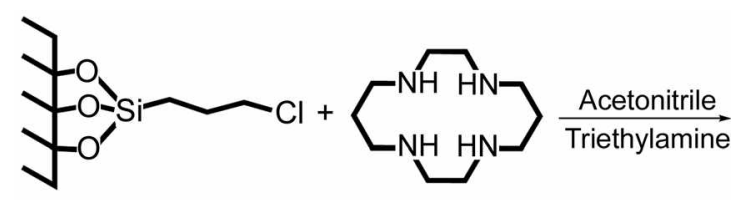

Clpr-SBA-15

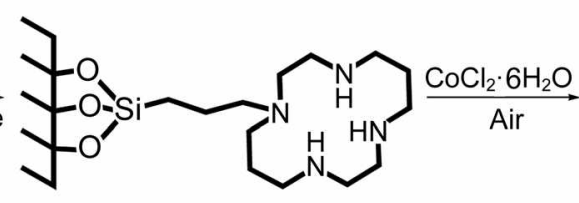

Cyclam-SBA-15

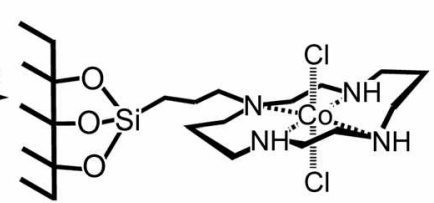

Co(cyclam)-SBA-15

Scheme 1. Schematic illustration for the synthesis of Co(cyclam)-SBA-15.
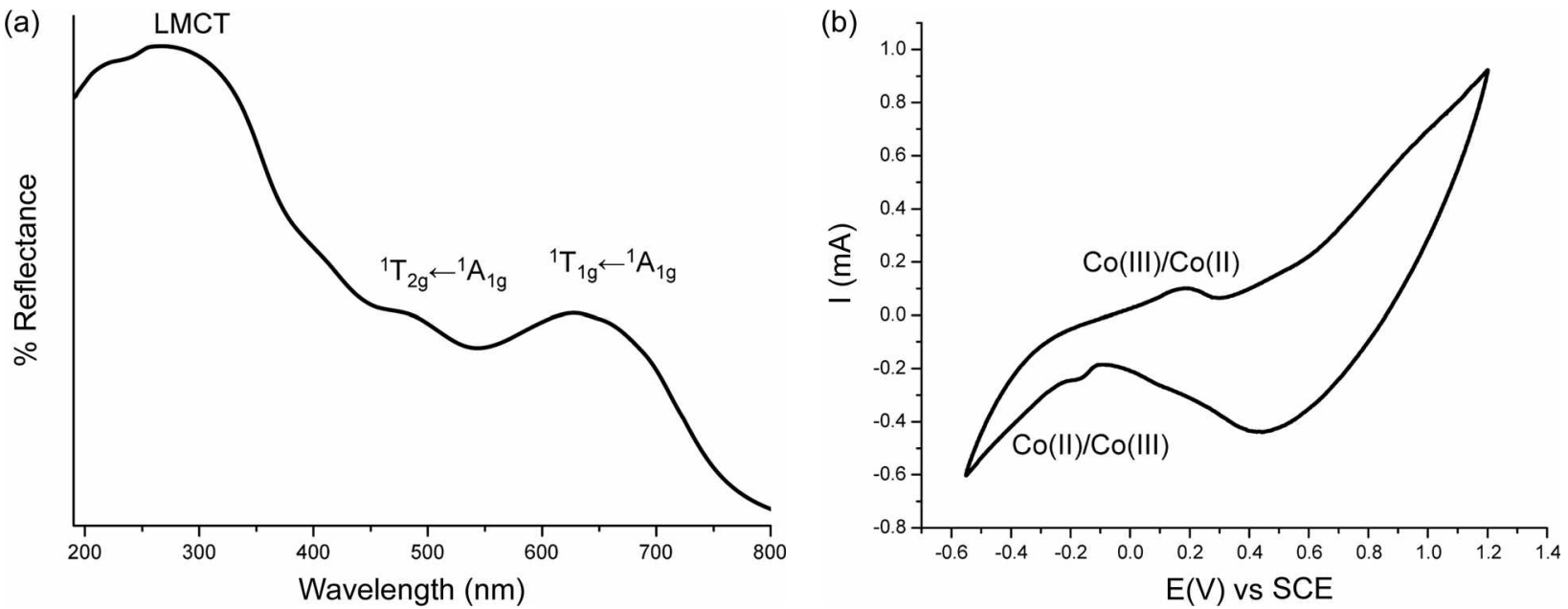

Figure 3. UV-Vis DRS spectra and cyclic voltamogram of Co(cyclam)-SBA-15. 
(a)

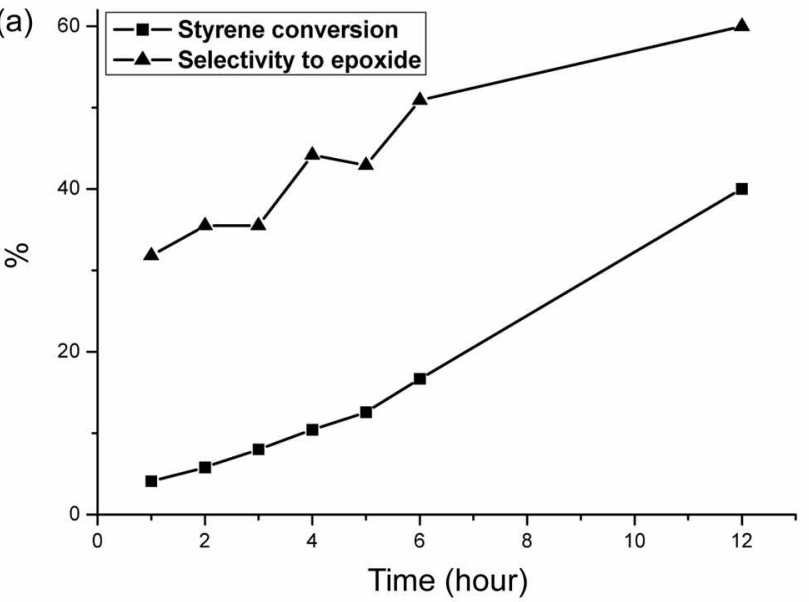

(b)

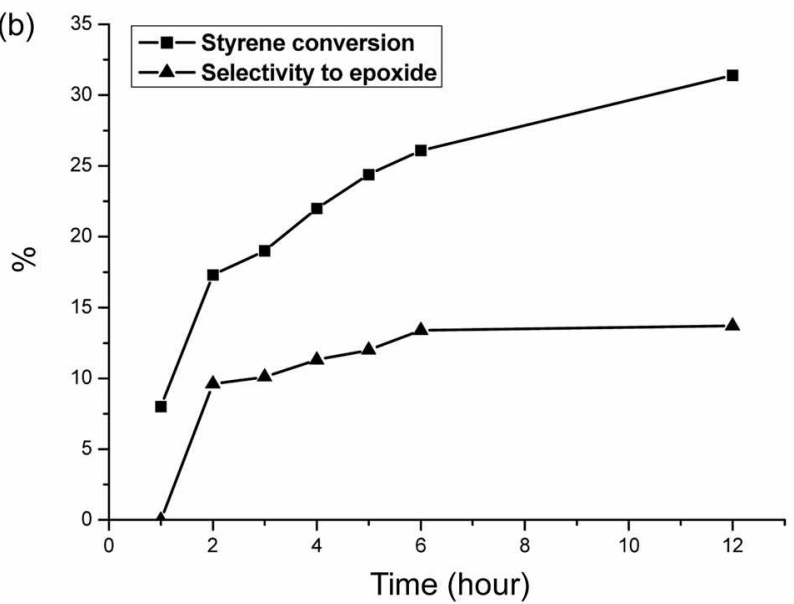

Figure 4. Time course for the styrene opexidation over $\mathrm{Co}$ (cyclam)-SBA-15 catalyst: (a) with TBHP and (b) with $\mathrm{H}_{2} \mathrm{O}_{2}$ as the terminal oxidant.

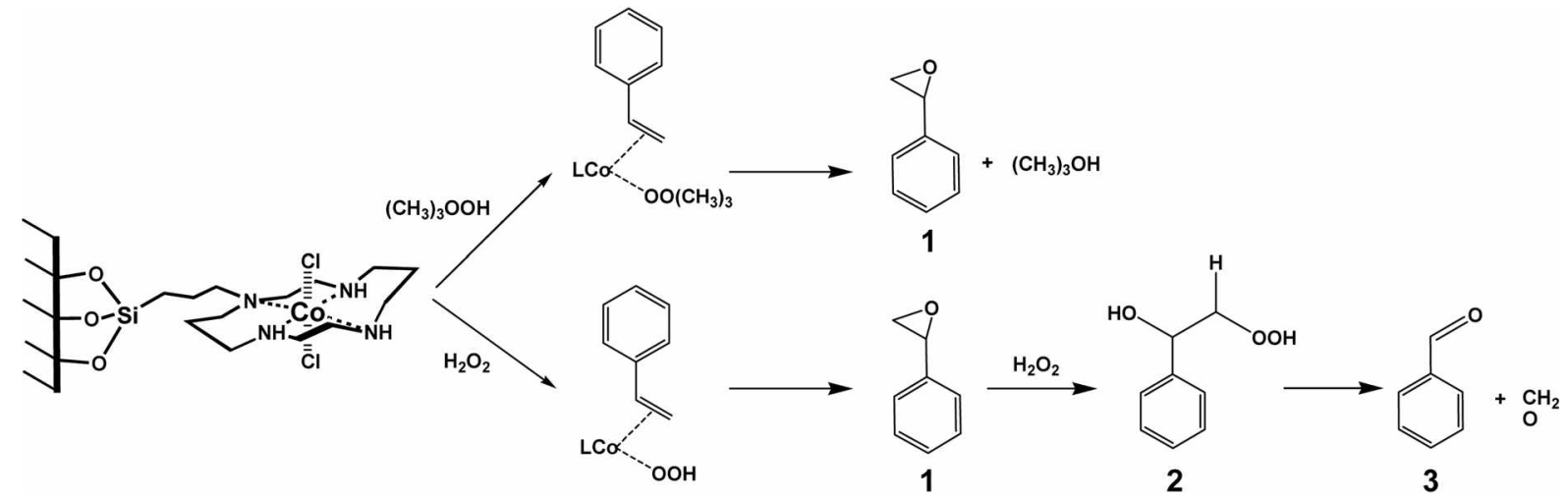

Figure 5. Proposed inechanisins for the oxidation of styrene with $\mathrm{TBHP}$ and $\mathrm{H}_{2} \mathrm{O}=$ over $\mathrm{Co}$ (cyclann) functionalized $\mathrm{SB} A-15$.

$\mathrm{nm}$ and $1723 \mathrm{~nm}$ also indicated the addition of $\mathrm{CH}_{2}$ moiety upon the substitution of cyclam for $\mathrm{Cl}$. The NIR spectra of Co(cyclam)-SBA-15 was found to be similar to that of the Cyclam-SBA-15. This means that the structure of tethered cyclam did not change during the cobalt complexation reaction which was done in an ethanolic solution with continuing air bubbling in order to oxidize the Coli $(\mathrm{cyclam})$ to $\mathrm{Co}^{\text {III }}$ (cyclam) complex. ${ }^{7}$

The Co(cyclam)-SBA-15 catalyst showed three absorption peaks at UV-Vis region 659,485 and $260 \mathrm{~nm}$ for $\mathrm{T}_{1 \mathrm{~g}} \leftarrow$ ${ }^{\prime} \mathrm{A}_{1 \mathrm{~g}}, \mathrm{~T}_{20} \leftarrow{ }^{\prime} \mathrm{A}_{1 \mathrm{~g}}$ and ligand to metal charge transfer (LMCT) electronic transition, respectively and could be attributed to electronic transitions of trans- $\mathrm{Co}\left(\mathrm{Cl}_{2}\right)(\text { cyclam })^{+}$complex (Fig. 3a). ${ }^{19}$ The cyclic voltammogram of carbon paste electrode modified with $\mathrm{Co}(\mathrm{cyclam})-\mathrm{SBA}-15$ in $0.1 \mathrm{M} \mathrm{LiClO}_{4}$ solution in acetonitrile showed two reversible redox peaks which correspond to the $\mathrm{Co}$ (II)/Co(III) couple with $\mathrm{E}_{\mathrm{a}}=0.17$ $V$ vs SCE and $E_{c}=-0.16 \mathrm{~V}$ vs SCE, the $I_{a}$ and $I_{c}$ were found to be $0.11 \mathrm{~mA}$ and $-0.25 \mathrm{~mA}$, respectively. The $\mathrm{E}_{1 / 2}=0.005$ $v s$ SCE was found to be less positive than that of free cobalt(cyclam) complex, indicating that the immobilized Co(cyclam) complex is easier to be reduced than that the free one. The larger peak separation on the cyclic voltamogram of the immobilized cobalt(cyclam) complex as com- pared to the free one could be due to the slow kinetic of the electrochemistry reaction on the immobilized sample. ${ }^{20}$

Catalytic Epoxidation of Styrene. The catalytic activity of the obtained Co(cyclam)-SBA-15 was investigated through the epoxidation of styrene with tert-butyl hydroperoxide and hydrogen peroxide as terminal oxidants. Figure 4 . show the time-course for the styrene epoxidation over Co(cyclam)SBA- 15 catalyst. The conversion of styrene was reached $40 \%$ with $66 \%$ selectivity to the styrene oxide after 12 hours reaction time when tent-butyl hydroperoxide was used as an oxidant. And the other products were found to be benzaldehyde, benzoic acid, and diol. On the other hand, styrene oxidation with hydrogen peroxide gave significant lower selectivity to epoxide with nearly similar styrene conversion. Base on $\mathrm{GC} / \mathrm{GC}-\mathrm{MS}$ analysis, the major product was found to be a benzaldehyde. From the product distribution it could be concluded that the styrene oxidation with TBHP and $\mathrm{H}_{2} \mathrm{O}_{2}$ over $\mathrm{Co}$ (cyclam)-SBA- 15 was mainly proceed through the $\mathrm{Co}^{\mathrm{II}}$-peroxo intennediate and concerted oxygen atom transfer to the vinyl group of styrene to yield the epoxide. ${ }^{45.12}$ The proposed mechanism for the oxidation of styrene with TBHP and $\mathrm{H}_{2} \mathrm{O}_{2}$ is illustrated in Figure 5. The reversible redox cycle between $\mathrm{Co}^{\mathrm{Il}}-\mathrm{CO}^{\mathrm{III}}$ oxidation state which involved in the formation of peroxo species and oxygen 
atom transfer was being the key factor to these oxidation catalytic cycles. ${ }^{5}$ Similar mechanisms via the metal peroxo intermediates have been proposed in the literatures. ${ }^{4,22,23}$

The formation of benzaldehyde could be observed either when TBHP or $\mathrm{H}_{2} \mathrm{O}_{2}$ was used as the oxidant. The formation of benzaldehyde could be resulted from the nucleophilic attack of oxidants to the styrene oxide following by decomposition of the peroxystyrene intermediate (2) ${ }^{2+25}$ Being a mild oxidant egent, TBHP is more selective toward the formation of styrene oxide because only small quantity of the formed styrene oxide was converted into benzaldehyde. On other hand, the formed styrene oxide is more readily converted into benzaldehyde due to the nucleophilic attack of stronger oxidant agent like $\mathrm{H}_{2} \mathrm{O}_{2}$ (Figure 5). In the case of $\mathrm{H}_{2} \mathrm{O}_{2}$ as the oxidant, benzaldehyde can also result by a radical mechanism from the direct oxidative cleavage of the styrene side chain double bond.

\section{Conclusion}

Cobalt(III) species in the form of Co cyclam complex has been successfully immobilized onto SBA-15 mesoporous silica surface through the chemical modification of chloropropyl tethered SBA-15 which was synthesized through the direct synthesis under microwave irradiation. The Co(cyclam)SBA-15 showed high catalytic activity in the oxidation of styrene with tert-butyl hydroperoxide which gave $40 \%$ conversion and $66 \%$ selectivity to the styrene oxide after 12 hours. The main pathway was proposed via the formation of $\mathrm{Co}^{\mathrm{II}}$-peroxo intermediate following by the concerted oxygen atom transfer to the double bond of the styrene.

Acknowledgement. This work was supported by Inha University Research (2006).

\section{References}

1. Chang, J.-S.; Hwang. J. S.; Park, S.-E. Res. Chent Internted.
$2003,29,921$

2. Ying, J. Y; Mehnert, C. P.; Wong, M. S. Angew. Chem., Int. Ed. $1999,38,56$.

3. De Vos, D. E.; Dams, M.; Sels, B. F.; Jacobs, P. A. Chent Rev: $2002,102,3615$.

4. Pruf, T.; Macquarrie, D. J.; Clark, J. H. App. Catal. $A$ 2004, 276, 29.

5. Koola, J. D.; Kochi, J. K. J. Org. Chent. 1987, 52, 4545.

6. Lindoy, L. F. The Chenistry of Macrocyclic Ligand Conplexes; Cambridge University Press: Cambridge, 1989.

7. Harrowfield, J. M.; Kim, Y,; Koutsantonis, G. A.; Lee, Y. H.; Thuéry, P. Inorg. Chem. 2004, 43, 1689 .

8. Nam, W. Kim, H. J.; Kim, S. H.; Ho, R. Y. N.; Valentine, J. S. Inorg. Chem. 1996, 35, 1045.

9. Barefield, E. K.; Wagner, F.; Herlinger, A. W.; Dahl, A. R. In Inorganic Synthesis; Basolo, F., Ed.; McGraw-Hill: New York, 1976; Vol. 16, p 220 .

10. Wight, A. P.; Davis, M. E. Chem, Rev, 2002, 102, 3589.

11. Han, S.-C.; Sujandi; Park, S.-E. Butl. Korean Chem. Soc. 2005. 26,1381 .

12. Materi-Farahani, M.; Farzaneh. F.; Ghandi, M. J. Mol. Catal. A $2006,243,170$.

13. Park, S.-E.; Kim, D. S.; Chang, J.-S.; Kim, W. Y. Catal. Today: $1998,44,30 \mathrm{l}$.

14. Park, S.-E.; Chang, J.-S.; Hwang, Y. K.; Kim, D. S.; Jhung, S. H.; Hwang. J. S. Catal. Strv. Asia 2004, 8, 91 .

15. Hwang. Y. K.; Chang, J.-S.; Kwon, Y.-U.; Park, S.-E. Micro. Meso. Mater. 2004, 68, 21 .

16. Zhao, D.; Huo, Q.; Feng, J.; Chmelka, B. F.; Stucky, G. D. J. Am Chem. Soc. 1998, 120,6024.

17. Sujandi; Han, S.-C.; Han, D.-S.; Jin, M. J.; Park, S.-E. submitted for publication.

18. Xu, L.; Fu, H.; Schlup, J. R. J. Ant. Chem. Soc. 1994, /16, 2821.

19. Bosnich. B.; Poon, C. K.; Tobe, M. L. Inory. Chem. 1965, 4, 1102.

20. Hung, Y.; Martin, L. Y.; Jackels, S. C.; Tait, A. M.; Busch, D. H. J. Am. Chem. Soc. 1977, 99, 4029.

21. Simon, E.; L'Haridon, P.; Pichon, R.; L'Her, M. Inorg. Chin. Acta $1998,282,173$.

22. Lin, Y. H.; Williams, I. D.; Li, P. Appl. Cotal. A 1997, 150, 221 .

23. Sheldon, R. A.; Van Door, J. J. Catal. 1973, 31, 427.

24. Huleaa, V; Dumitriu, E. Appl. Catal. A 2004, 277, 99.

25. Farzaneh. F.; Taghavi, J.; Malakooti, R.; Ghandi. M. J. Mol. Catol. A: Chem. 2006, 244, 252. 